\title{
New lessons on the Sudd hydrology learned from remote sensing and climate modeling
}

\author{
Y. A. Mohamed ${ }^{1,2}$, H. H. G. Savenije ${ }^{1,3}$, W. G. M. Bastiaanssen ${ }^{4}$, and B. J .J. M. van den Hurk ${ }^{5}$ \\ ${ }^{1}$ UNESCO-IHE, P.O. Box 3015, 2601 DA Delft, The Netherlands \\ ${ }^{2}$ IWMI Nile Basin and Eastern Africa Sub Region, P.O. Box 5689, Addis Ababa, Ethiopia \\ ${ }^{3}$ Delft University of Technology, Stevinweg 1, 2628 CN Delft, The Netherlands \\ ${ }^{4}$ ITC (currently with WaterWatch), Generaal Foulkesweg 28, 6703 BS Wageningen, The Netherlands \\ ${ }^{5}$ KNMI, P.O. Box 201, 3730 AE De Bilt, The Netherlands
}

Received: 21 June 2005 - Published in Hydrol. Earth Syst. Sci. Discuss.: 16 August 2005

Revised: 24 March 2006 - Accepted: 12 June 2006 - Published: 10 July 2006

\begin{abstract}
Despite its local and regional importance, hydrometeorological data on the Sudd (one of Africa's largest wetlands) is very scanty. This is due to the physical and political situation of this area of Sudan. The areal size of the wetland, the evaporation rate, and the influence on the micro and meso climate are still unresolved questions of the Sudd hydrology.

The evaporation flux from the Sudd wetland has been estimated using thermal infrared remote sensing data and a parameterization of the surface energy balance (SEBAL model). It is concluded that the actual spatially averaged evaporation from the Sudd wetland over 3 years of different hydrometeorological characteristics varies between 1460 and $1935 \mathrm{~mm} / \mathrm{yr}$. This is substantially less than open water evaporation. The wetland area appears to be $70 \%$ larger than previously assumed when the Sudd was considered as an open water body. The temporal analysis of the Sudd evaporation demonstrated that the variation of the atmospheric demand in combination with the inter-annual fluctuation of the groundwater table results into a quasi-constant evaporation rate in the Sudd, while open water evaporation depicts a clear seasonal variability. The groundwater table characterizes a distinct seasonality, confirming that substantial parts of the Sudd are seasonal swamps.

The new set of spatially distributed evaporation parameters from remote sensing form an important dataset for calibrating a regional climate model enclosing the Nile Basin. The Regional Atmospheric Climate Model (RACMO) provides an insight not only into the temporal evolution of the hydro-climatological parameters, but also into the land surface climate interactions and embedded feedbacks. The impact of the flooding of the Sudd on the Nile hydroclimatology has been analysed by simulating two land surface scenarios
\end{abstract}

Correspondence to: Y. A. Mohamed

(yasir1@unesco-ihe.org) (with and without the Sudd wetland). The paper presents some of the model results addressing the Sudd's influence on rainfall, evaporation and runoff of the river Nile, as well as the influence on the microclimate.

The paper presents a case study that confirms the feasibility of using remote sensing data (with good spatial and poor temporal coverage) in conjunction with a regional climate model. The combined model provides good temporal and spatial representation in a region characterized by extremely scarce ground data.

\section{Introduction}

Wetland development projects (conservations, resource utilization, etc.) require an accurate knowledge of the water balance components over the wetland: precipitation, evaporation, inflow, outflow and interaction with groundwater. Similarly, evaporation and biophysical characteristics of the wetland are required to better understand its interaction and feedback with the atmosphere. Usually evaporation from a wetland is a major component of its water budget, though complex to determine (Linacre et al., 1970).

Remote sensing techniques are increasingly employed to estimate land surface evaporation (see a review in Choudhury, 1989; Kustas and Norman, 1996; Menenti, 2000; Kustas et al. 2003; Coureault et al., 2005). The technique is even more attractive to derive evaporation and biophysical characteristics over wetlands, characterized by difficult accessibility. The actual evaporation $\left(E_{a}\right)$ from wetland includes all evaporation forms: open water evaporation, plant transpiration and wet/dry soil evaporation. A distinctive advantage of remote sensing measurement is that it provides an optimal spatial distribution from several kilometers to a few

Published by Copernicus GmbH on behalf of the European Geosciences Union. 
meters. On the other hand, a major limitation is that the temporal distribution of satellite-based estimates is poor, and that interpolation techniques are necessary to define evaporation between satellite overpasses. In this respect hydrological and climate models once properly calibrated can be very effective to fill in the gaps between satellite overpasses.

World wide, numerous field experiments have been executed to measure and model wetland evaporation. However, results remain site-specific and are difficult to extrapolate in space and time. In general, wetland evaporation is estimated based on either direct measurements or through modeling. Examples of direct measurements are: Rijks (1969), Josè et al. (2001) and Jacobs et al. (2002) using energy balance techniques (Bowen ratio and eddy correlation methods). The water balance approach to estimate wetland evaporation either as the balance of the whole wetland or as a measuring technique, e.g., Lysimeter and water tank experiments was used by Butcher (1938), Lott and Hunt (2001). Applications of remote sensing to estimate wetland evaporation exist but are very limited (e.g., Bauer et al., 2002).

Some of the wetland evaporation studies assume that wetland $E_{a}$ resembles open water evaporation $E_{w}$ (Penman, $1963)$; others assume that $E_{a}$ resembles the potential evaporation $E_{p}$, i.e. evaporation from vegetative cover with no water constraint (e.g., Lott and Hunt, 2001). In such cases $E_{a}$ is computed from routine meteorological data using formulae like: Penman 1948, Priestley-Taylor, Penman-Monteith (P-M), among others (see a review in Jacobs et al., 2002). However, a wetland system is a mixed composition of marshland vegetation types, open water bodies and (un)saturated soil. Depending on the vegetation canopy structure, the wetland vegetation may intercept the incoming solar radiation, and can shelter the blowing wind. The question is: Does the transpiration provided by the wetland vegetation offset the deficit caused by the vegetation shading or exceeds it (Gilman, 1994)?

The Sudd is a huge interconnected wetland located on the Nile. About half of the White Nile river flow spills over and evaporates from the Sudd. Water resources planners searching for additional Nile water have had the intention to build short cut channels to divert river water from upstream the Sudd (e.g. the Jonglei canal). Despite the intensive studies conducted to understand the Sudd hydrology and assess the impacts of water diversion (e.g., JIT, 1954; Howel et al., 1988) still many questions remain unresolved. The exact evolution of the Sudd boundary is unknown. There are attempts to define its size based on areal surveys (JIT, 1954), based on hydrological models (Sutcliffe and Parks, 1999), based on remote sensing (Travaglia et al., 1995), or based on remote sensing and hydrological models (Mohamed et al., 2004). Similarly, the literature shows a wide range of evaporation estimate over the Sudd, between 1530 to $2400 \mathrm{~mm} / \mathrm{yr}$ (Butcher 1938, Mijahid, 1948, Sutcliffe and Parks 1999).

An important unresolved question, is how much the moisture feedback to the atmosphere is? Here also different re- searchers show no consensus. The JIT (1954) and Howell et al. (1988, p. 375) suggest no impact is expected on the regional climate by draining part of the Sudd by the Jonglei canal. Eltahir (1989), Eagleson (1986) among others suggest that the evaporation from the Sudd would surely be felt climatically over a wider region.

This paper presents new insight into the Sudd hydrology derived from remote sensing energy balance modeling and numerical climate modeling. The spatial and temporal variability of evaporation and biophysical properties have been determined from NOAA-AVHRR LAC (National Oceanic Atmospheric Administration - Advanced Very High Resolution Radiometer Local Area Coverage) satellite images, using the SEBAL algorithm (Surface Energy Balance Algorithm for Land). The derived evaporation provides an essential input to hydrological and climate models, which provides further in-depth understanding of the wetland system and its impact on the surroundings. Section 2 of the paper gives a brief description of the Sudd wetland. Section 3 shows the evaporation result and how it has been calculated. Section 4 presents some results of the Sudd impacts on local and regional climate. Finally a summary of the results and conclusions is outlined in Sect. 5.

Parts of this manuscript have been published in previous articles. Detailed analysis of the spatial variability of evaporation over the Sudd derived from remote sensing was discussed in Mohamed et al. (2004). The regional climate modeling part and assessment of the Sudd's impact on the Nile hydroclimatology was discussed in Mohamed et al. (2005a) and Mohamed et al. (2005b). However, the main objective of this article is to present the piece-wise results published previously pertinent to the Sudd question into one paper, supported by new computations for 2 additional years. Furthermore, new results on the temporal evolution of the Sudd evaporation and associated biophysical prosperities provides additional knowledge on the seasonality of the Sudd evaporation compared to open water evaporation, an assumption persisted for decades on the Sudd studies.

\section{Study area: the Sudd wetland}

The Sudd wetland is one of the biggest swamps in Africa, neighboring the smaller wetlands of the Bahr el Ghazal and the Machar marshes (Fig. 1). The permanent swamps, usually close to the main river course are permanently wet. However, substantial parts of the Sudd are seasonal swamps created by flooding of the Nile or when ponds are filled seasonally with rainwater. Depending on the definition, the surface area is approximately 30000 to $40000 \mathrm{~km}^{2}$. The area of the permanent swamps has tripled after the immense flooding of the early 1960's (Sutcliffe and Parks, 1999). The Sudd terrain is generally flat, composed of clayish soils, usually poor in nutrients. Rain falls in a single season, lasting from April to November and varying in the Sudd area from about 


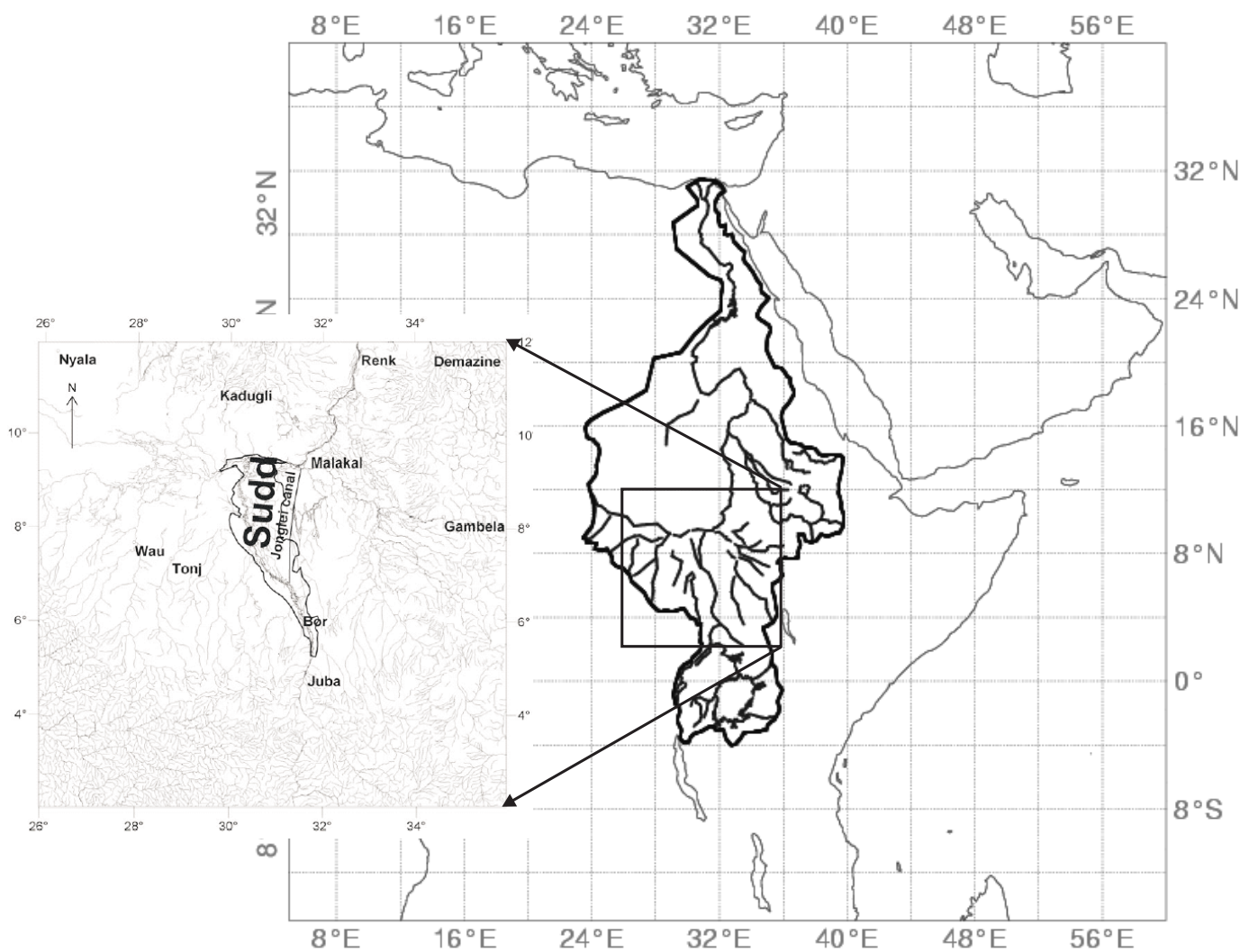

Fig. 1. Location of the Nile Basin and the Sudd wetland.

$900 \mathrm{~mm} / \mathrm{yr}$ in the south to $800 \mathrm{~mm} / \mathrm{yr}$ in the north. Temperatures average to $30-33^{\circ} \mathrm{C}$ during the dry season, dropping to an average of $26-28^{\circ} \mathrm{C}$ in the rainy season.

The Sudd environment supports a variety of vegetation species including: Cyperus papyrus, Phragmites (reed), Typha swamps (cattail), Wild rice (Oryza longistaminata). The Echinochloa pyramidalis grasslands dominate the seasonally inundated floodplains. Beyond the floodplain, Hyparrhenia rufa grasslands cover the rain-fed wetlands. Acacia seyal and Balanites aegyptica woodlands border the floodplain ecosystem (Denny, 1991). The Sudd wetland is very important to the pastoral economy of the local inhabitants (cattle grazing), and the swamps support rich biota, including different bird and mammal species.

The average annual Nile flow in and out of the Sudd for the period $1961-1983$ is 49 and $21 \mathrm{Gm}^{3} / \mathrm{yr}$, respectively. The difference can be ascribed to evaporation, and an amount of $28 \mathrm{Gm}^{3} / \mathrm{yr}$ of evaporative depletion has attracted planners to build short cut channels for bypassing the river water. The Jonglei canal phase 1 is the first phase in a series of proposed water conservation projects. The canal $(360 \mathrm{~km}$ long, $2 / 3$ completed) has an average bed width of $38 \mathrm{~m}, 4$ to $8 \mathrm{~m}$ deep, with a ground slope varying between 7 to $12 \mathrm{~cm} / \mathrm{km}$. If Nile water resources upstream of the Sudd are pushed into the Jonglei canal, there will be less flooding and a wetland area of approximately $30 \%$ will be drained. The additional gained water amounts to about $4 \mathrm{Gm}^{3} / \mathrm{yr}$ (JIT, 1954; Howell et al., 1988). Due to the war in the southern part of Sudan the work on the canal stopped in 1983.

\section{Estimation of the Sudd evaporation}

Accurate determination of the Sudd evaporation is hindered by its immense size and difficult accessibility. Earlier attempts to measure evaporation in the Sudd started by the experiments of Butcher (1938) and Migahid (1948) and the calculations of Hurst and Philips (1938). The JIT (1954) and Sutcliffe and Parks (1999) estimated the Sudd evaporation as being similar to open water evaporation. In this study, the actual evaporation of the Sudd is estimated through the application of the SEBAL remote sensing algorithm that utilizes NOAA-AVHRR images.

\subsection{The SEBAL algorithm}

The SEBAL algorithm is an energy-partitioning algorithm over the land surface, which estimates the actual evaporation from satellite images (Bastiaanssen et al., 1998a). The minimum input requirements are routine meteorological station data. The satellite image provides an excellent spatial cover- 


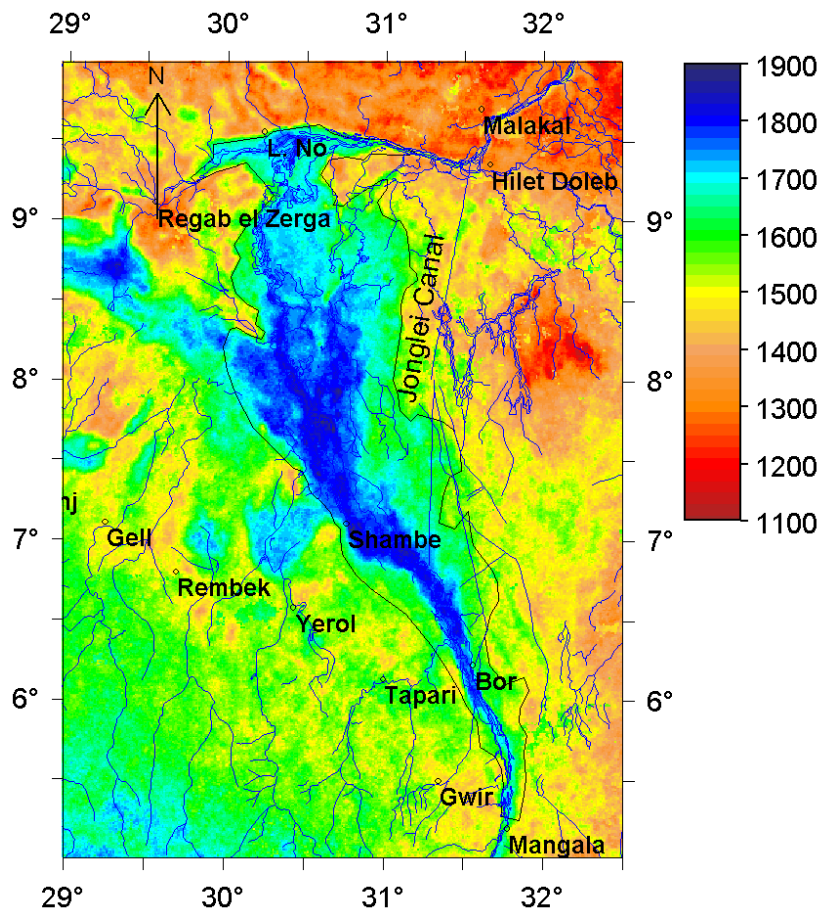

Fig. 2. Mean annual evaporation over the Sudd ( $\mathrm{mm} / \mathrm{yr})$, mean of 1995, 1999 and 2000.

age with a resolution of $1 \mathrm{~km}$. The temporal coverage is limited to the time of the satellite overpass. So, the derived parameters need to be extrapolated to daily and monthly values using various techniques. In this paper, the temporal characteristic of the Sudd evaporation has been studied by repetitive calculations for years 1995, 1999 and 2000.

The SEBAL algorithm computes the latent heat flux as the residue of the energy balance equation:

$\lambda E_{a}=R_{n}-G_{0}-H$

where $R_{n}$ is the net radiation over the surface $\left(\mathrm{W} / \mathrm{m}^{2}\right), G_{0}$ is the soil heat flux $\left(\mathrm{W} / \mathrm{m}^{2}\right), H$ is the sensible heat flux $\left(\mathrm{W} / \mathrm{m}^{2}\right)$, $\lambda E_{a}$ is the latent heat flux $\left(\mathrm{W} / \mathrm{m}^{2}\right)$ and $\lambda$ is the latent heat of vaporization $(\mathrm{J} / \mathrm{Kg})$. The major SEBAL steps required to produce an evaporation map are: (i) Pre-processing of the satellite image (radiometric correction, geometric correction and removal of cloud pixels), (ii) Computation of the Soil Vegetation Atmosphere Transfer (SVAT) parameters, including: surface albedo $r_{0}$, Leaf Area Index $I_{L A}$, thermal infrared emissivity $\varepsilon_{0}$, surface roughness $z_{0 m}$, land surface temperature $T_{0}$, (iii) Computation of $R_{n}$ and $G_{0}$, (iv) The sensible heat $H$ is computed based on an iteration procedure that describes buoyancy effects on the aerodynamic resistance of the land surface $r_{a h}$, (v) Computation of instantaneous latent heat flux $\lambda E_{a}$ and instantaneous evaporative fraction $\Lambda$. The evaporative fraction, is a key parameter in SEBAL to express energy partitioning:

$\Lambda=\frac{\lambda E_{a}}{\lambda E_{a}+H}=\frac{\lambda E_{a}}{R_{n}-G_{0}}=\frac{1}{1+\beta}$

where $\beta$ is the Bowen ratio $\left(H / \lambda E_{a}\right)$. The evaporative fraction shows less variation during the daytime than the Bowen ratio as was investigated over the savannah landscape in Kenya by Farah et al. (2004). Detailed description of the SEBAL algorithm including verification results can be found in Bastiaanssen et al. (1998a, b, 2005); Allen et al. (2002) among others. The main assumption to obtain daily evaporation from the instantaneous SEBAL results is that the instantaneous evaporative fraction is equal to its daily value integrated over a period of $24 \mathrm{~h}$ (e.g., Brutsaert and Sugita, 1992), although newer versions of SEBAL allow to make this flexible for the inclusion of intermittent cloud cover and advection processes. The daily soil heat flux is assumed negligible as it balances out during day and night. The daily net radiation is obtained from routine meteorological data at the ground stations. The daily evaporation is calculated as the instantaneous evaporative fraction times the daily net radiation. The monthly evaporation results are obtained by extrapolating daily evaporation data assuming that the daily ratio of actual evaporation to reference evaporation is valid also for a monthly time step (Allen et al., 2002). Daily and monthly reference evaporation were computed by the Penman-Monteith equation based on routine weather data measured at ground stations in the Sudd area. It can be seen that extrapolation from daily to monthly evaporation involves assumptions which may not be completely satisfied in reality. The extrapolation to monthly maps is based on three daily evaporation maps on day: 5; 15; and 25 (Mohamed et al., 2004). If the soil moisture condition changes immediately after a given day, the ratio may not be representative for the coming 10 days. Knowing this limitation, however, we believe that the error introduced is small, and that there is a high probability of positive and negative values to cancel out. However, correct monthly evaporation maps should be based on daily maps for the entire month. Availability of suitable NOAA-AVHRR images and the very long calculation process drove us to adopt this approach. We may conclude that compared to the assumption of constant evaporative fraction for the whole month, used by some researchers, this approach is considered adequate.

\subsection{Spatial variability of the Sudd evaporation}

More than 115 satellite images have been processed with SEBAL to obtain monthly evaporation maps for the years 1995 , 1999 and 2000. The 3 years have different hydrometeorological conditions. Figure 2 gives the mean annual evaporation from the 3 years of data.

The derived evaporation results over the Sudd can be verified through water balance computations. The areal size of the Sudd is one of the key problems for assessing the water 
balance as it varies during the different seasons of the year. There is an ongoing debate on the Sudd boundaries, and also the boundary between the Sudd and the neighboring Bahr el Ghazal swamps is highly questionable. The annual evaporation map can be considered as a suitable indicator for the annual wetland area. However, seasonally the area can be different (Mohamed et al., 2004). The Sudd boundary based on this assumption is shown in Fig. 2. Please note that, no distinction is made between seasonal and permanent swamps, however, a clear distinction is seen between the swamp area (influenced by river flooding) and the surrounding area subject to rainfall alone. The delineated Sudd area is $38.6 \mathrm{Gm}^{2}$, which is $74 \%$ larger than the value used in the past when the Sudd was considered an open water body.

The monthly water balance of the Sudd for the years 1995, 1999 and 2000 is computed by:

$\frac{d S}{d t}=Q_{\text {in }}+P-E_{a}-Q_{\text {out }}$

where $d S / d t$ is the monthly change of storage volume. $Q_{\text {in }}$ is the estimated monthly river inflow at Mangala based on Lake Victoria outflows (corrected for Lake Kayoga and Lake Albert contributions) and the torrents flow between lake Albert and Mangala. The monthly rainfall $P$ over the Sudd is taken as the average of Juba, Malakal and Wau. Outflow $Q_{\text {out }}$ has been derived from the inflow based on the equation of Howell et al. (1988, p. 497). Evaporation $E_{a}$ is estimated by SEBAL over the Sudd area. The results of the monthly water balance are given in Appendix A. The results show acceptable annual closure error of $0.1,-0.6$ and $-3.0 \%$ of $E_{a}$ for the 3 years 1995, 1999 and 2000, respectively.

Although satisfactory validation results of SEBAL were obtained for 3 different catchments (Sudd, Bahr El Ghazal, and the Sobat) for year 2000 as discussed in (Mohamed et al., 2004), the water balance calculation given here confirmed the obtained results by data from additional two years over the Sudd. The three years 1995, 1999, and 2000, were critically selected to represent dry, wet, and medium hydrological condition over the Sudd, respectively.

3.3 Temporal variability of evaporation and biophysical properties over the Sudd

The seasonal variability of the Sudd $E_{a}$ is given in Fig. 3 (mean monthly values of the 3 years). For comparison, the open water evaporation $E_{w}$ is plotted in the same figure. $E_{w}$ has been calculated with the Penman-Monteith equation (Eq. 4) using the Sudd meteorological data and the physical properties of water. The data reveals a clear seasonality of $E_{w}$ (high during the dry season and low during the rainy months), whereas $E_{a}$ is remarkably stable. As mentioned above, the Sudd wetland is not a pure water body, instead it is a swampy area partially covered with wetland vegetation. Secondly, it is composed of permanent swamps (wet all year around) located close to the river course, and seasonal parts

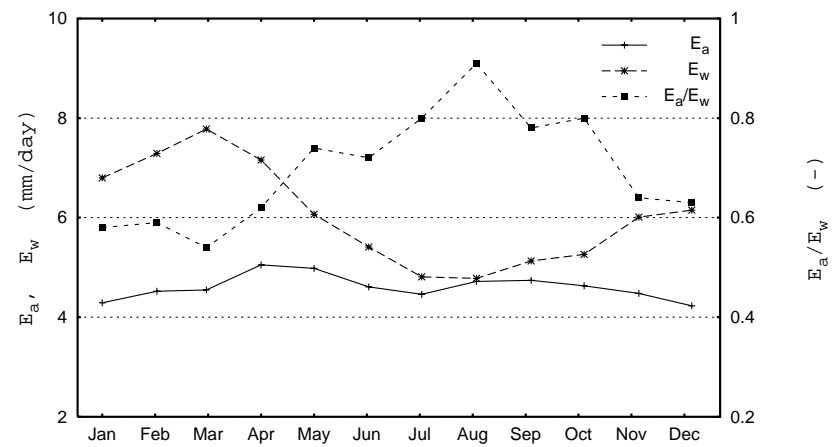

Fig. 3. Monthly fluctuations of actual Sudd evaporation $E_{a}$, open water evaporation $E_{w}(\mathrm{~mm} /$ day $)$, and the ratio $\left(E_{a} / E_{w}\right)$, averaged values over the Sudd (mean of years 1995, 1999, 2000).

created by river flooding and precipitation. So knowledge of vegetation characteristics and their impact on the canopy resistance and aerodynamic resistances $r_{c}$ and $r_{a}$ respectively are key to explaining the range of $E_{a}$ values in relation to open water evaporation $E_{w}$. This can be explained by further investigation of the biophysical properties of the Sudd wetland in relation to open water properties. The relationship between biophysical properties and the evaporative flux can be derived from the Penman-Monteith energy balance combination equation:

$$
E T_{o}=\frac{0.408 \Delta\left(R_{n}-G\right)+\gamma \frac{900}{T+273} U_{2}\left(e_{a}-e_{d}\right)}{\Delta+\gamma\left(1+0.34 U_{2}\right)}
$$

where $\Delta\left(\mathrm{Pa} / \mathrm{C}^{\circ}\right)$ is the slope of the saturated vapor pressure curve, $c_{p}\left(\mathrm{~J} / \mathrm{kg} / \mathrm{C}^{\circ}\right)$ is the specific heat at constant air pressure, $\rho_{a}\left(\mathrm{~kg} / \mathrm{m}^{3}\right)$ is the air density, $\left(e_{s}-e_{a}\right)$ is the vapour pressure deficit in $(\mathrm{Pa}), \gamma\left(\mathrm{Pa} / \mathrm{C}^{\circ}\right)$ is the psychrometric constant. $r_{s}$ $(\mathrm{s} / \mathrm{m})$ is a mixture of $r_{c}(\mathrm{~s} / \mathrm{m})$ that dictates canopy transpiration, soil resistance that controls soil evaporation and the resistance for open water (usually zero when the water body is unpolluted). $r_{s}$ is equal to $r_{c}$ if soil and water surfaces are completely covered by vegetation in a wetland ecosystem.

The biophysical parameters of the Sudd were calculated from the AVHRR images using semi-empirical formulae, which are part of SEBAL algorithm (Mohamed et al., 2004). The parameters include: $r_{0}, I_{L A}, \varepsilon_{0}$ and $z_{0 m}$. The bulk surface resistance $r_{s}$ is calculated backward from the SEBAL $E_{a}$ using the inverse Penman-Monteith equation (Eq. 4). The areal mean values of the biophysical parameters over the entire Sudd averaged for the years 1995, 1999 and 2000 are presented in Fig. $4 \mathrm{a}$ and $\mathrm{b}$. The temporal variability clearly reflects seasonal climate influence $\left(R_{n},\left(e_{s}-e_{a}\right), \Delta\right)$, and the hydrological condition caused by precipitation and Nile flooding as depicted in Fig. 5a and b. The data of Fig. 5a and $b$ were derived from ground gauging stations around the Sudd area.

Figure 4a shows a clear seasonality of $I_{L A}$, in accordance with the rainfall season and river flooding as presented in 
(a)

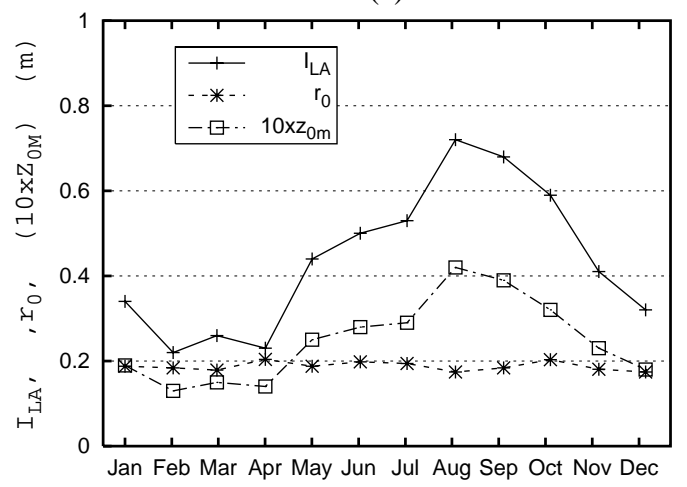

(b)

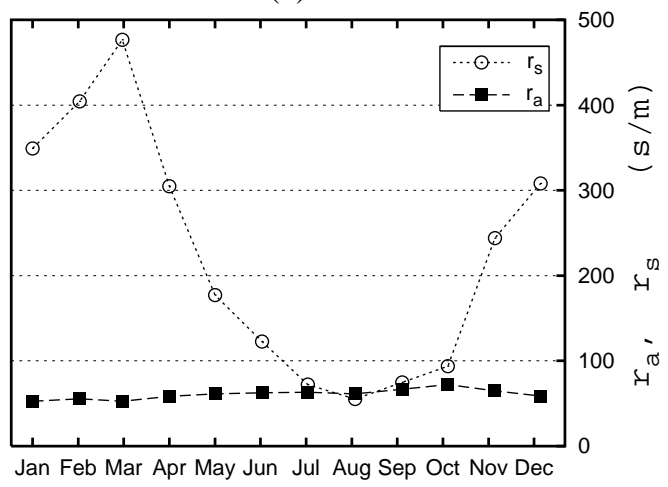

Fig. 4. (a) Monthly fluctuations of Leaf Area Index $I_{L A}(-)$, albedo $r_{0}(-)$, and (10 times) surface roughness height $10 \times z_{0 m}$ (m). (b) Monthly fluctuations of surface resistance $r_{s}$ and aerodynamic resistance $r_{a}(\mathrm{~s} / \mathrm{m})$, averaged values over the Sudd (mean of years 1995, 1999, 2000).

Fig. 5b. High $I_{L A}$ values occur during the peak rainy season. The roughness height $z_{0 m}$ follows the $I_{L A}$ curve (by construction) and has a peak value in August and lowest value in the dry months of February-April. The albedo $r_{0}$ behaves fairly stable in time. The surface thermal infrared emissivity $\varepsilon_{0}$ shows small seasonal variability between 0.92 in the dry season to 0.96 in the rainy season (not shown here).

The lowest $\left(e_{s}-e_{a}\right)$ is recorded during the rainy season elapsing from July-October, while highest values are recorded in the dry season from November-April (Fig. 5a). Due to the higher cloud cover during periods of higher solar radiation in August-October, the net radiation remains fairly stable over time (Fig. 5a). This has an important impact on $E_{a}$, which usually obeys the temporal pattern of $R_{n}$. The slope of the vapor pressure curve $\Delta$ shows small variability throughout the seasons $\left(0.18\right.$ to $0.24 \mathrm{kPa} /{ }^{\circ} \mathrm{C}$ ) (data not shown), because the temperature is fairly stable throughout the year.

The hydrological control on evaporation depends on moisture availability in the root zone, which governs the surface resistance $r_{s}$. Figure $4 \mathrm{~b}$ shows that the surface resistance $r_{s}$ has a distinct seasonal variability, which is consistent with the inter-seasonal variation of $\left(e_{s}-e_{a}\right)$ and $I_{L A}$. The lowest $r_{s}$ values are associated with the lowest $\left(e_{s}-e_{a}\right)$ and the highest $I_{L A}$ during the wet months July-October, and the reverse occurs during the dry months February-April. The variability of $r_{s}$ also correlates with the river flow regime and the calculated ground water table fluctuations. A qualitative assessment of the temporal variability of the groundwater level over the Sudd derived from satellite data and water balance calculations is presented in Fig. 6. It shows a profound seasonal variation (lowest in May and highest in October), demonstrating that the majority of the Sudd is non-inundated and has a seasonal decaying vegetation system. Only the lower parts near the riverbed are permanently saturated. The lower groundwater table reduces the soil moisture in the root zone and increases the leaf water potential, i.e. higher $r_{s}$ values.
Therefore, the possible explanation for the quasi-steady variation of $E_{a}$ in contrast with $E_{w}$, is that net radiation varies only between 120 to $150 \mathrm{~W} / \mathrm{m}^{2}$ and that $\left(e_{s}-e_{a}\right)$ and $r_{s}$ have cancelling effects due to their natural feedback mechanisms as described by Jarvis (1976) and Stewart (1988). This is an important conclusion for this tropical wetland in Sudan.

\section{Regional climate modeling}

An analysis of the Sudd hydrology by a regional climate model (RCM) is essential to understand the land-surface climate interaction in the region and assess the impact of future scenarios (e.g. draining the swamps). It is widely believed that large land use changes can impose changes on regional climate. Similarly, climate change directly influences basin hydrology, and subsequently the water resources. Evaporation from a large area contributes to atmospheric moisture through moisture recycling and enhances precipitation downwind (Savenije, 1995; Schär et al., 1999). While many researchers support positive soil moisture atmosphere feedback, i.e., an increased soil moisture anomaly favors an increase of precipitation (e.g., Betts et al., 1999), there are researchers who claim a negative soil moisture feedback, which is attributed to increased convective precipitation due to enhanced buoyancy over the dried soils (e.g., Ek and Holtslag, 2004). Soil moisture-atmosphere feedback in a region depends on the climate system of the region and how it has been modeled. The literature shows no consensus on the impact of draining the Sudd on the regional water cycle.

In this section we present the experience of the development of an RCM over the Nile Basin to study the role the Sudd wetland has on regional atmospheric circulation processes. Two simulations are compared: the present climatology (control run CTL) in which the Sudd is seasonally flooded, and a drained Sudd scenario in which the Nile inflow into the Sudd is stopped by means of a by pass that 


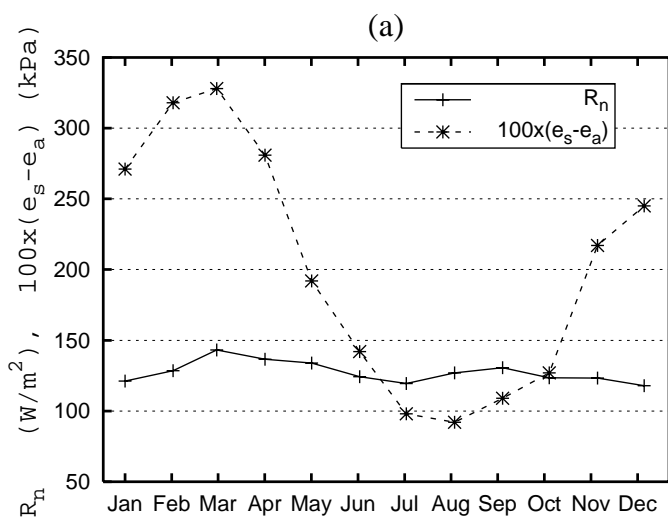

(b)

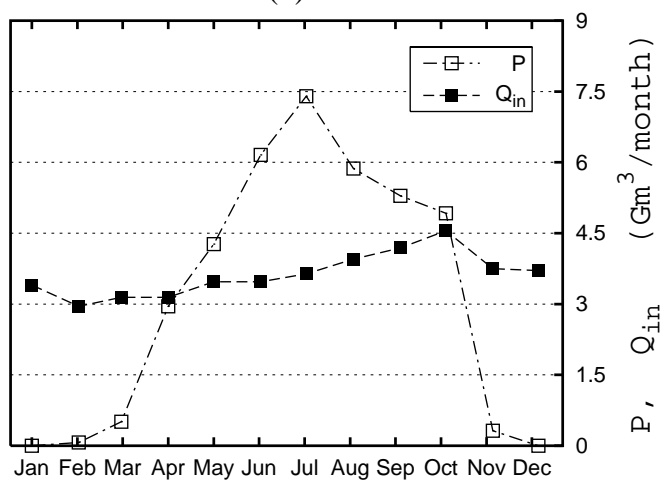

Fig. 5. (a) Monthly fluctuations of net surface radiation $R_{n}\left(\mathrm{~W} / \mathrm{m}^{2}\right), 100$ times vapor pressure deficit $100 \times\left(e_{s}-e_{a}\right)(\mathrm{kPa})$. (b) Monthly fluctuations of inflow $Q_{\text {in }}$ and rainfall $P\left(\mathrm{Gm}^{3} / \mathrm{month}\right)$, averaged values over the Sudd (mean of years 1995, 1999, 2000).

prohibits any Nile water to flow into the marshland (Drained run DRA).

The RCM is based on RACMO (Regional Atmospheric Climate Model), described in Mohamed et al. (2005a). It is the main limited area model used by KNMI (The Royal Netherlands Meteorological Institute) for climate research. The model extends between $10^{\circ} \mathrm{E}$ to $54.4^{\circ} \mathrm{E}$ and $12^{\circ} \mathrm{S}$ to $36^{\circ} \mathrm{N}$ (Fig. 1), and has a horizontal resolution of $50 \mathrm{~km}$, including 31 levels in the vertical. The initial and lateral boundary conditions are taken from the ECMWF ERA-40 reanalysis data. The model has been adjusted to simulate the spilling of the Nile water over the Sudd by routing the flow generated from upstream catchments to 15 grid points that represent the Sudd wetland. The simulation period extends from 1995 to 2000 . The model has been validated against various observational datasets including: radiation, precipitation, runoff, and evaporation. The default RACMO settings were first modified based on a series of a one year simulations aimed at: modifying land-cover representation; smoothening of orography; reduction of hydraulic conductivity; adjustment of aerosols to increase incoming short wave radiation (Sect. 3.2 of Mohamed et al., 2005a). The SEBAL estimations of evaporative fraction, soil moisture and evaporation have been used to adapt the input parameters of the RACMO land surface model, notably the (i) the minimum canopy resistance has been reduced, (ii) a higher soil moisture content has been established by introduction of flooding, (iii) the soil layer depth has been increased for larger storage capacity and (iv) the hydraulic conductivity has been decreased to reduce deep percolation. These changes in the model significantly affect the partitioning of net radiation into surface sensible and latent heat fluxes. The detailed validation results are given in Mohamed et al. (2005a). In general, the model provided a sound representation of the hydroclimatological processes over the region. The model has been run for a second scenario with the Sudd completely drained (Mohamed et al., 2005b).

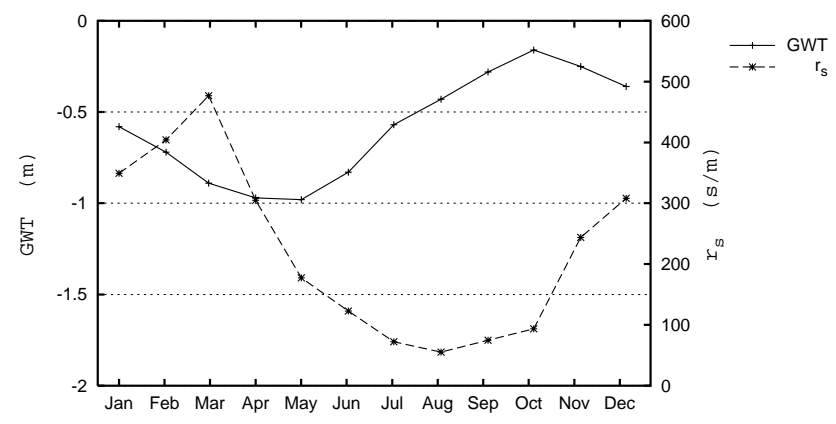

Fig. 6. Monthly fluctuations of the areal average groundwater table GWT $(\mathrm{m})$, and surface resistance $r_{s}(\mathrm{~s} / \mathrm{m})$, averaged values over the Sudd (mean of years 1995, 1999, 2000).

\subsection{Impact of the Sudd wetland on the Nile hydroclimatol-} ogy

Complete diversion of all natural Nile water inflow into the Sudd may have several implications on hydroclimatology both locally and regionally. During the dry period, December to March, soil moisture and evaporation over the Sudd are reduced substantially in the DRA run. This causes a reduction of the screen level humidity $(R H)$ by 30 to $40 \%$ compared to the CTL run, while the difference is small $(<10 \%)$ in the wet season June to September (Fig. 7a and b). The incoming solar energy, which is partitioned into latent and sensible heat in the CTL scenario, with minimal soil heat in the wetland, will be partitioned mainly into sensible heat at low values of soil moisture during the dry season. This results in a rise of the screen level temperature $(T)$ by 4 to $6^{\circ} \mathrm{C}$ on the drained parts in the dry season (Fig. 7c), while it shows a small rise of $0.5^{\circ} \mathrm{C}$ in the wet season (Fig. $7 \mathrm{~d}$ ). There are small changes of $R H$ and $T$ outside the Nile Basin on the eastern part of the Congo Basin (increased $R H$ and reduced $T$ ). A possible explanation for this is that air passing over the drained Sudd (from east to west in the dry season) has higher water uptake 


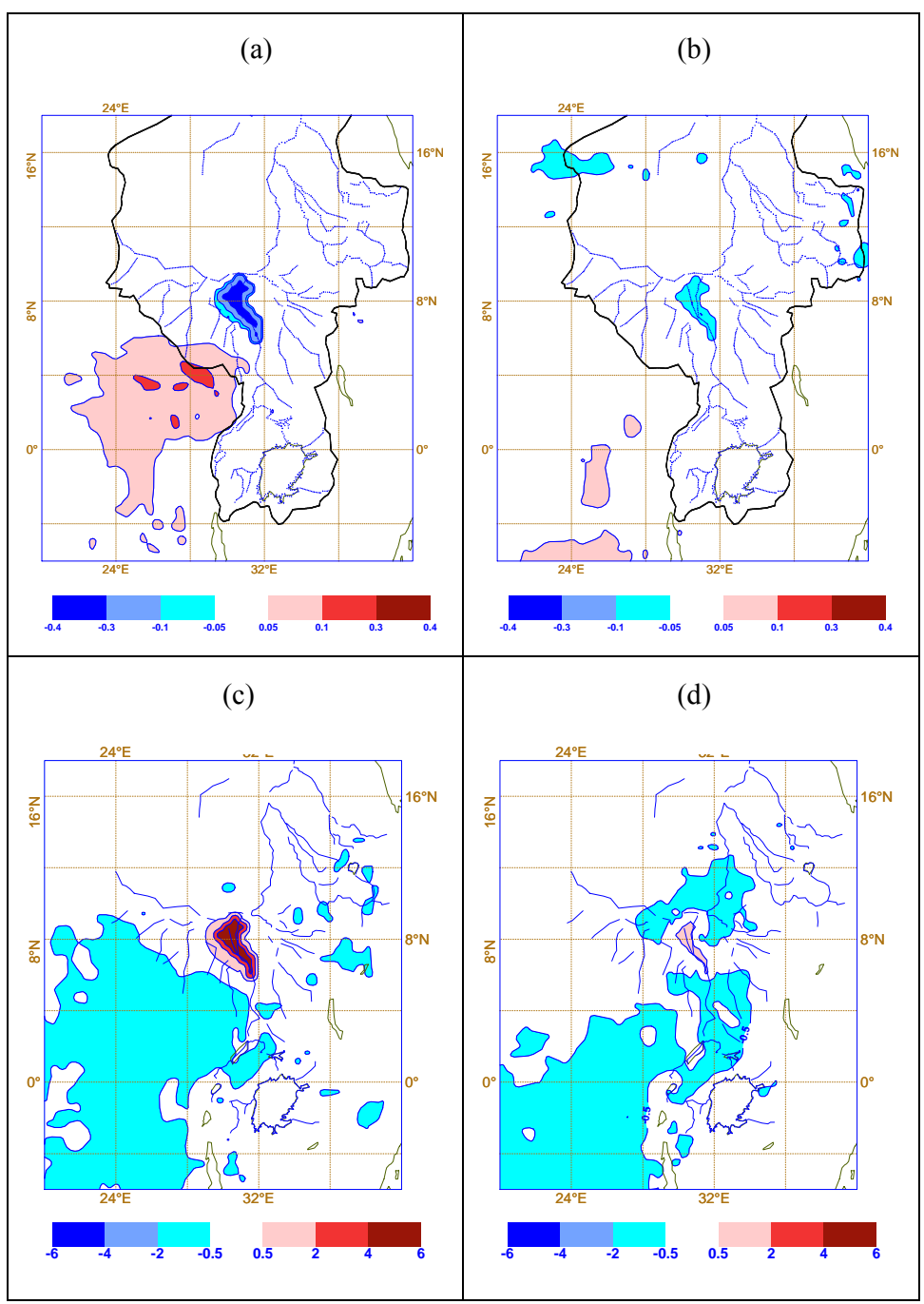

Fig. 7. (a) Change of the relative humidity $R H$ in the dry season, (b) change of $R H$ in the wet season (-), (c) change of temperature $T$ in the dry season, (d) change of $T$ in the wet season $\left({ }^{\circ} \mathrm{C}\right)$. Mean seasonal values of 1995 to 2000.

capacity, which enhances water advection from further south, while enhanced surface evaporation provides additional $R H$ and subsequently reduces $T$. During the rainy season, the impact of draining the Sudd is much less influencing since both the Sudd itself and the surrounding area are wet from the rain.

It appears that the role of the Sudd on the Nile Basin hydrological budget is negligible. The inter-annual variability of: $P, E, R$, and $d S / d t$ (change of sub-surface moisture storage) of the Nile catchment at the Aswan outlet is more distinct than the impact of draining the Sudd wetlands (Fig. 8). The error bars represent one standard deviation (std) around the mean. The difference in $P, E, R$ and $d S / d t$ for the DRA run, is much smaller than the standard deviation, indicating an insignificant change compared to the inter-annual variability in the 6 years record. Detailed inspection of model results at smaller time steps (6 hourly) reveals that the stability of the regional climate could be sensitive to draining the Sudd wetlands. A possible explanation of the slight increase in $P$ for the drained Sudd scenario is due to the enhanced convection over the dried soils.

Although the evaporation rate over the Sudd is about 3 times the average rate in the surrounding area, volume-wise the ratio of the Sudd evaporation is very small compared to regional evaporation. Secondly, the Sudd evaporation constitutes only around $1 \%$ of the volume of the atmospheric moisture flux over the Nile region, which is mainly of oceanic origin. Obviously theses results could have been expected in view of the small size of the Sudd relative to the Nile Basin (about $1 \%$ ). So, it can be concluded that in terms of mass balance, the impact of the Sudd on the Nile's atmospheric budget is negligible. 
(a) Precipitation $\mathrm{P}$

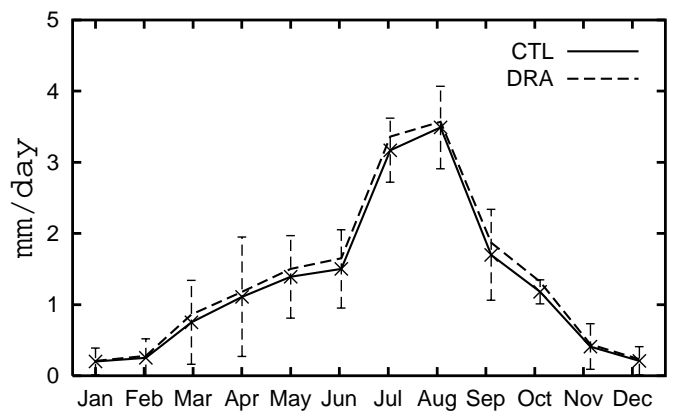

(c) Runoff $\mathrm{R}$

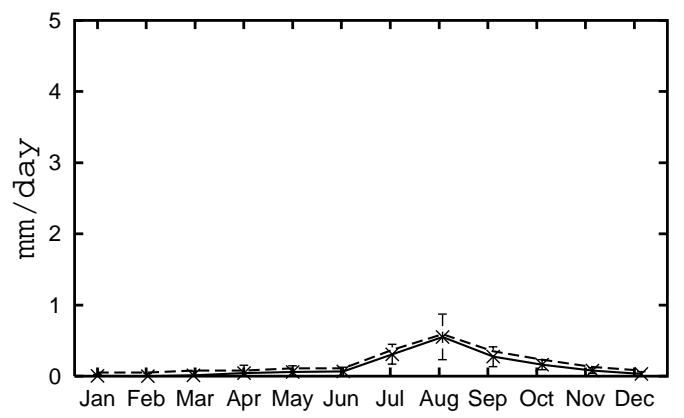

(b) Evaporation $\mathrm{E}$

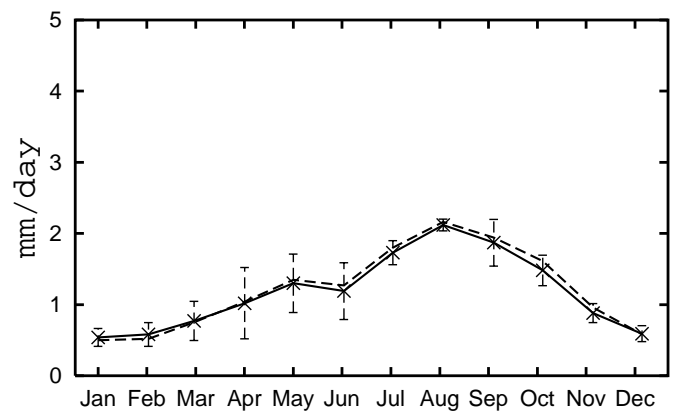

(d) change of sub-surface storage dS/dt

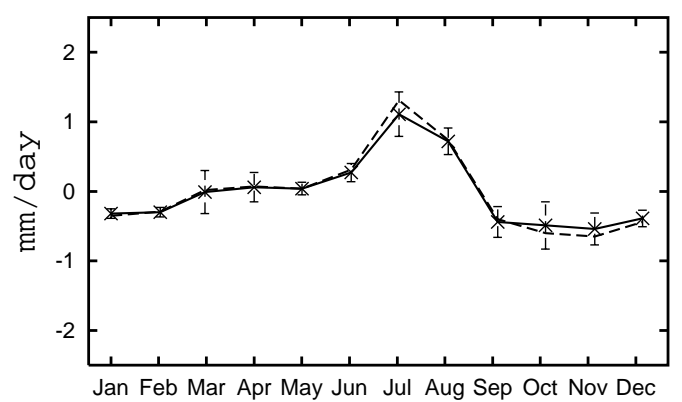

Fig. 8. The hydrological budget terms of the Nile at Aswan (mm/day), mean annual cycle 1995-2000: (a) precipitation, (b) evaporation, (c) runoff, (d) change of sub-surface moisture storage. The error bars represent one std around the mean of the CTL data.

Table 1. Annual water budget terms of the area upstream of the White Nile at Malakal in $\mathrm{Gm}^{3} / \mathrm{yr}$ (mean annual values of 1995 to 2000 ).

\begin{tabular}{lccccc}
\hline & $Q_{\text {in }} \mathrm{Gm}^{3} / \mathrm{yr}$ & $P \mathrm{Gm}^{3} / \mathrm{yr}$ & $E \mathrm{Gm}^{3} / \mathrm{yr}$ & $d S / d t \mathrm{Gm}^{3} / \mathrm{yr}$ & $Q_{\text {out }} \mathrm{Gm}^{3} / \mathrm{yr}$ \\
\hline Observed & 0 & - & - & 0 (assumed) & 33 \\
CTL & $0+(53)$ & 899 & 879.7 & -12.5 & 85.2 \\
DRA & 0 & 964 & 902.1 & -15.5 & 78.3 \\
\hline
\end{tabular}

The additional Nile water provided at the outlet downstream of the Sudd is literally the whole river runoff generated upstream of the Sudd for the DRA run, while for the CTL run, the major part of this upstream runoff is evaporated over the Sudd, in particular during the dry season. By diverting water off the Sudd, evaporation becomes entirely dependent on rainfall. Part of the rainfall will contribute to runoff and to groundwater recharge, and the remaining part is evaporated.

The White Nile catchment upstream of the outlet at Malakal (includes Sudd, Sobat and Bahr el Ghazal) has been selected to assess the amount of additionally gained runoff, (catchment area is $1.48 \times 10^{6} \mathrm{~km}^{2}$ ). Table 1 shows the water budget terms of the White Nile at Malakal. Inflow is zero since the whole catchment upstream of Malakal has been considered and there is no substantial inter-basin transfer. For the CTL run, $53 \mathrm{Gm}^{3} / \mathrm{yr}$ has been distributed over the 15 grid points of the Sudd $(4.1 \mathrm{~mm} /$ day $)$ to represent the
Nile flooding over the wetland. This is slightly higher than the observed Nile flow at Juba of $49 \mathrm{Gm}^{3} / \mathrm{yr}$ (mean between 1961 and 1983). Here the observed runoff is used, rather than the computed runoff, since RACMO underestimates runoff at this location $\left(21 \mathrm{Gm}^{3} / \mathrm{yr}\right)$. In the DRA run no water has been distributed over the Sudd.

Since the $53 \mathrm{Gm}^{3} / \mathrm{yr}$ volume has been supplied externally to simulate river routing and flooding over the wetlands, it is not part of the natural runoff yield. To assess the runoff difference between the two runs, the artificially supplied water $\left(53 \mathrm{Gm}^{3} / \mathrm{yr}\right)$ is subtracted from the CTL runoff at Malakal, which yields to $32.2 \mathrm{Gm}^{3} / \mathrm{yr}(85.2-53)$, Therefore, the runoff difference between CTL and DRA runs amounts to $46.1 \mathrm{Gm}^{3} / \mathrm{yr}(78.3-32.2)$. This number is the extra outflow that can be expected to flow into the Nile downstream of the Sudd (for no flooding case). However, a correction is needed as it was found that RACMO has $10 \mathrm{Gm}^{3} / \mathrm{yr}$ more evaporation than SEBAL. So, a correction of the CTL runoff by 
$10 \mathrm{Gm}^{3} / \mathrm{yr}$ seems plausible. It is assumed that RACMO overestimation of evaporation is at the expense of the computed runoff. In the DRA run there is no overestimation of evaporation in the dry season because of the absence of river flooding. This implies that the "best guess" impact of draining the whole Sudd wetlands yields an extra Nile discharge of 46$10=36 \mathrm{Gm}^{3} / \mathrm{yr}$. This is somewhat more than the long-term 1961-1983 mean losses over the Sudd of $29 \mathrm{Gm}^{3} / \mathrm{yr}$ given in Sutcliffe and Parks (1999). The discrepancy is well understood from the noted model deficiencies and bias corrections applied.

The table shows that for this catchment both $P$ and $E$ are relatively higher in the CTL run than the DRA run. As discussed above for the whole Nile catchment (Fig. 8), a possible explanation of the small increase in $P$ in the drained Sudd scenario is due to an enhanced convective precipitation over the dried soils, and that the relatively higher precipitation produces an increased evaporation. Over the Sudd wetland alone, evaporation is very much different in the two runs: 68 and $21 \mathrm{Gm}^{3} / \mathrm{yr}$ in the CTL and DRA runs, respectively, while precipitation is almost similar 22 and $21 \mathrm{Gm}^{3} / \mathrm{yr}$, respectively. Obviously, less moisture is available for evaporation from the Sudd in the DRA scenario.

It is to be mentioned that RACMO computation of catchment runoff over the White Nile shows to be extremely sensitive to inaccuracy of either $P$ or $E$. This is due to the exceptionally small runoff coefficient over this vast catchment (Mohamed et al., 2005a). For both the CTL and DRA runs, RACMO overestimates the runoff at Malakal (Table 1), and underestimates runoff at Juba (just upstream of the Sudd, see Fig. 1). The annual runoff computed at Juba is 21 and $24 \mathrm{Gm}^{3} / \mathrm{yr}$ for CTL and DRA, respectively, while the observed long-term (1961-1983) mean is $49 \mathrm{Gm}^{3} / \mathrm{yr}$. Although RACMO is not suitable for distributed hydrological analysis - it shows to be very instrumental for estimating the major changes in the water balance.

Based on the design capacity of the canal, the uncompleted Jonglei canal planned to divert $4 \mathrm{Gm}^{3} / \mathrm{yr}$. Although not modeled in this study, the general perception is that an amount of $4 \mathrm{Gm}^{3} / \mathrm{yr}$, which is $8 \%$ of longer-term inflow into the Sudd, will drain about 30\% of the Sudd wetland (Howell et al., 1988). In view of the atmospheric modeling results obtained, it can be stated safely that $30 \%$ reduction of the Sudd area will have no alternation of the regional rainfall patterns, while the impact on micro-climatic and near-surface weather conditions during the dry season can be expected (analogous to the obtained results).

\section{Conclusions}

Despite the importance of the Sudd wetland, both for the local environment, an international bird paradise and as an expected additional supplier of the Nile water, still many questions related to its hydrology and impact on the regional hy- droclimatology are unresolved. This paper presents a contribution towards better understanding the Sudd hydrology and its impact on the sub-continental atmospheric circulation processes.

Remote sensing techniques (SEBAL algorithm) proved to be instrumental in defining net radiation and actual evaporation over the Sudd (characterized by scanty ground observations). Monthly actual evaporation and soil moisture maps during 3 years of different hydrometeorological conditions (1995, 1999 and 2000) have been prepared. The area of the Sudd based on an average annual evaporation characteristic is $38.6 \mathrm{Gm}^{2}$. The annual evaporation rate for 1995,1999 and 2000 is 1460,1935 and $1636 \mathrm{~mm} / \mathrm{yr}$, respectively (hence 57 , $74,63 \mathrm{Gm}^{3} / \mathrm{yr}$ ). The Sudd actual evaporation $E_{a}$ doesn't show much seasonal variability, whereas open water body evaporation $E_{w}$ clearly follows a seasonal climatic variation. The $E_{a}$ value of the Sudd is quasi-steady state, which can be ascribed to the lack of seasonality of net radiation and the canceling effect between the vapor pressure deficit and surface resistance throughout the season. The distinct seasonality of the surface resistance over the Sudd can be explained by the seasonality of the atmospheric vapor pressure deficit and availability of soil moisture due to rainfall variability and Nile flooding.

The interaction of the Sudd with the atmosphere has been studied with regional climate model simulations. The RACMO model has been calibrated using various datasets including SEBAL outputs on evaporation and related parameters. Two scenarios (with and without flooding) have been simulated for the period 1995-2000. Evaluation of the results from the two simulations has shown that draining the entire Sudd will have a significant impact on the microclimate. The relative humidity will drop by 30 to $40 \%$, and the local temperature rises by 4 to $6^{\circ} \mathrm{C}$ during the dry season. During the wet season the impact of the Sudd can hardly be discerned, because the surrounding area is saturated by rain. The simulated results show that the impact of the Sudd on the regional hydrological budget of the Nile Basin (precipitation, evaporation, runoff and sub-surface storage) is negligible and insignificant compared to the inter-annual variability of these parameters. The net gain of the Nile water by complete diversion of the Nile water from the Sudd would be an additional $\sim 36 \mathrm{Gm}^{3} / \mathrm{yr}$, which is more than the observed Nile evaporation over the Sudd $\left(29 \mathrm{Gm}^{3} / \mathrm{yr}\right)$.

Further research is desired to confirm the Sudd evaporation estimates against ground observations. Distributed hydrological modeling of the Sudd is needed to better understand the spatial and temporal evolution of the permanent and seasonal swamps. For the regional climate modeling it would be interesting to repeat the numerical experiment for a longer time span ( $40 \mathrm{yr}$ ), and finer model resolution (smaller than $50 \mathrm{~km}$ grid). However, the main conclusions derived here are likely to be confirmed rather than discarded, since the hydrological fluxes to and from the Sudd are relatively small compared to the atmospheric fluxes. 


\section{Appendix A}

Table A1. Monthly water balance of the Sudd wetland for 1995, units in $\mathrm{Gm}^{3} /$ month.

\begin{tabular}{lrrrrr}
\hline Month & $P$ & $E_{a}$ & $Q_{\text {in }}$ & $Q_{\text {out }}$ & $d S / d t$ \\
\hline Jan & 0.00 & 4.42 & 2.95 & 1.50 & -2.97 \\
Feb & 0.12 & 3.95 & 2.57 & 1.40 & -2.67 \\
Mar & 0.65 & 5.15 & 2.73 & 1.41 & -3.18 \\
Apr & 3.13 & 4.72 & 2.70 & 1.36 & -0.25 \\
May & 4.11 & 5.13 & 3.13 & 1.28 & 0.84 \\
Jun & 6.57 & 4.74 & 2.86 & 1.31 & 3.37 \\
Jul & 7.28 & 4.79 & 3.17 & 1.31 & 4.35 \\
Aug & 4.20 & 4.94 & 3.35 & 1.39 & 1.22 \\
Sep & 5.49 & 5.10 & 3.74 & 1.34 & 2.79 \\
Oct & 4.17 & 4.89 & 3.75 & 1.40 & 1.64 \\
Nov & 0.14 & 4.44 & 3.17 & 1.43 & -2.56 \\
Dec & 0.01 & 4.26 & 3.24 & 1.49 & -2.50 \\
\hline Total & 35.9 & 56.5 & 37.4 & 16.6 & 0.1 \\
\hline
\end{tabular}

Table A2. Monthly water balance of the Sudd wetland for 1999, units in $\mathrm{Gm}^{3} /$ month.

\begin{tabular}{lrrrrr}
\hline Month & $P$ & $E_{a}$ & $Q_{\text {in }}$ & $Q_{\text {out }}$ & $d S / d t$ \\
\hline Jan & 0.00 & 5.45 & 4.01 & 1.74 & -3.18 \\
Feb & 0.11 & 6.01 & 3.48 & 1.61 & -4.02 \\
Mar & 0.41 & 5.87 & 3.70 & 1.59 & -3.34 \\
Apr & 3.46 & 6.99 & 3.77 & 1.54 & -1.29 \\
May & 4.09 & 6.97 & 4.06 & 1.45 & -0.27 \\
Jun & 6.86 & 6.05 & 4.18 & 1.49 & 3.50 \\
Jul & 6.09 & 6.23 & 4.20 & 1.50 & 2.57 \\
Aug & 7.39 & 6.14 & 4.87 & 1.54 & 4.58 \\
Sep & 6.20 & 5.89 & 4.97 & 1.56 & 3.71 \\
Oct & 5.81 & 6.24 & 5.39 & 1.57 & 3.39 \\
Nov & 0.38 & 6.32 & 4.45 & 1.67 & -3.15 \\
Dec & 0.00 & 5.74 & 4.35 & 1.68 & -3.07 \\
\hline Total & 40.8 & 73.9 & 51.4 & 18.9 & -0.6 \\
\hline
\end{tabular}

Table A3. Monthly water balance of the Sudd wetland for 2000 , units in $\mathrm{Gm}^{3} /$ month.

\begin{tabular}{lrrrrr}
\hline Month & $P$ & $E_{a}$ & $Q_{\text {in }}$ & $Q_{\text {out }}$ & $d S / d t$ \\
\hline Jan & 0.00 & 5.45 & 3.23 & 1.62 & -3.84 \\
Feb & 0.00 & 4.80 & 2.81 & 1.47 & -3.47 \\
Mar & 0.45 & 5.21 & 2.98 & 1.46 & -3.23 \\
Apr & 2.26 & 5.45 & 2.94 & 1.41 & -1.65 \\
May & 4.60 & 5.64 & 3.23 & 1.33 & 0.87 \\
Jun & 5.05 & 5.33 & 3.38 & 1.36 & 1.74 \\
Jul & 8.83 & 4.98 & 3.55 & 1.35 & 6.04 \\
Aug & 6.03 & 5.53 & 3.64 & 1.41 & 2.73 \\
Sep & 4.19 & 5.21 & 3.86 & 1.43 & 1.40 \\
Oct & 4.79 & 5.77 & 4.52 & 1.46 & 2.09 \\
Nov & 0.43 & 4.68 & 3.61 & 1.48 & -2.11 \\
Dec & 0.00 & 5.05 & 3.53 & 1.51 & -3.04 \\
\hline Total & 36.6 & 63.1 & 41.3 & 17.3 & -2.5 \\
\hline
\end{tabular}

www.hydrol-earth-syst-sci.net/10/507/2006/
Acknowledgements. The material of this paper is part of a larger research study on moisture recycling over the Nile Basin funded by The International Water Management Institute IWMI, ITC Enschede and the UNESCO-IHE Delft. The climate modeling part of the study has been carried out at The Royal Netherlands Meteorological Institute (KNMI).

Edited by: A. Bardossy

\section{References}

Allen, R. G., Morse, A., Tasumi, M., Trezza, R., Bastiaanssen, W. G. M., Wright, J. L., and Kramber, W.: Evapotranspiration from a Satellite-BASED Surface energy balance for the Snake Plain Aquifer in Idaho, Proc. National USCID Conference, San Luis Obispo, California, pp. 16, 8-10 July 2002.

Bastiaanssen, W. G. M., Menenti, M., Feddes, R. A., and Holtslag, A. A. M.: The Surface Energy Balance Algorithm for Land (SEBAL): Part 1 formulation, J. Hydrol., (212-213) 198-212, 1998a.

Bastiaanssen, W. G. M., Menenti, M., Feddes, R. A., and Holtslag, A. A. M.: The Surface Energy Balance Algorithm for Land (SEBAL): Part 2 validation, J. Hydrol., (212-213) 198-212, 1998b.

Bastiaanssen, W. G. M., Noordman, E. J. M., Pelgrum, H., Davids, G., Thoreson, B. P., and Allen, R. G.: SEBAL Model with Remotely Sensed Data to Improve Water-Resources Management under Actual Field Conditions, ASCE J. Irrig. Drain. Eng., 131(1), 85-93, 2005.

Bauer, P., Brunner, P., and Kinzelbach, W.: Quantifying the Net Exchange of Water Between Land and Atmosphere in the Okavango Delta, Botswana, Conf. Proceedings Model Care 2002, Prag, Czech Republic, 581-584, 17-20 June 2002.

Betts, A. K., Ball, J. H., and Viterbo, P.: Basin-scale water and energy budgets for the Mississippi from the ECMWF reanalysis, J. Geophys. Res., 104D, 19293-19306, 1999.

Brutsaert, W. H. and Sugita, M.: Regional surface fluxes from satellite-derived surface temperatures (AVHRR) and radiosonde profiles, Boundary-Layer Meteorology, 58, 355-366, 1992.

Butcher, A. D.: The Sadd hydraulics. Technical report, Ministry of Public Works, Cairo, Egypt, 1938.

Choudhury, B. J.: Estimating evaporation and carbon assimilation using infrared temperature data: Vistas in modeling, in: Theory and applications in optical remote sensing, edited by: Asrar, G., John Wiley, New York, 628-690, 1989.

Coureault, D., Seguin, B., and Olioso, A.: Review about estimation of evapotranspiration from remote sensing data: from empirical to numerical modeling approach, Irrigation and Drainage Systems, 19, 3-4, 223-249, 2005

Denny, P.: Africa, in Wetlands, edited by: Finlayson, M. and Moser, M., International Waterfowl and Wetlands Research Bureau, Facts on File, Oxford, UK, pp. 115-148, 1991.

Eagleson, P. S.: The Emergence of Global-Scale Hydrology, Water Resour. Res., 22(9), 6s-14s, 1986.

Ek, M. B. and Holtslag, A. A. M.: Influence of Soil Moisture on Boundary Layer Cloud Development, J. Hydrometeorol., 5, 8699, 2004

Eltahir, E. A. B.: A Feedback Mechanism in Annual Rainfall in Central Sudan, J. Hydrol., 110 , 323-334, 1989. 
Farah, H. O., Bastiaanssen, W. G. M., and Feddes, R. A.: Evaluation of the temporal variability of the evaporative fraction in a tropical watershed, Int. J. Appl. Earth Obs. Geoinform., 5, 129-140. 2004.

Gilman, K.: Water balance of wetland areas, Conf. on "The balance of water - present and future", AGMET Gp. (Ireland) \& Agric. Gp. of Roy. Meteorol. Soc. (UK), Dublin, 123-142, 7-9 Sep 1994.

Howell, P. P., Lock, J. M., and Cobb, S. M. (Eds): The Jonglei canal: Impact and Opportunity. Cambridge University Press, UK, pp. 536, 1988.

Hurst, H. E. and Philips, P.: The hydrology of the Lake Plateau and Bahr el Jebel, The Nile Basin Vol. V, Government Press, Cairo, Egypt, 1938.

Jacobs, J. M., Mergelsberg, S. L., Lopera, A. F., and Myers, D. A.: Evapotranspiration from a wet prairie wetland under drought conditions: Paynes prairie preserve, Florida, USA, WELANDS, 22(2), 374-385, 2002.

Jarvis, P. G.: The interpretation of the variations in leaf water potential and stomatal conductance found in canopies in the field. Philosophical Transactions of the Royal Society of London, (B) 273, 593-610, 1976.

JIT: The Equatorial Nile Project and its effects in the AngloEgyptian Sudan. Report of the Jonglei Investigation Team, Sudan Government, Khartoum, 1954.

José, J. S., Meirelles, M. L., Bracho, R., and Nikonova, N.: A comparative analysis of the flooding and fire effects on the energy exchange in a wetland community (Morichal) of the Orinoco Llanos, J. Hydrol., 242 (3-4), 228-254, 2001.

Kustas, W. P. and Norman, J. M.: Use of remote sensing for evapotranspiration monitoring over land surfaces, Hydrol. Sci. J., 41(4) 495-515, 1996.

Kustas, W. P., Diak, G. R., and Moran, M. S.: Remote sensing of evaporation, Encyclopedia of Water Science, Marcel Dekker Inc., doi:10.108/E-EW120010313, 267-274, 2003.

Linacre, E. T., Hicks, B. B., Sainty, G. R., and Grauze, G.: The evaporation from a swamp, Agric. Meteorology, 7, 375-386, 1970.
Lott, R. B. and Hunt, R. J.: Estimating evapotranspiration in natural and constructed wetlands, Wetlands, 21, 614-628, 2001.

Migahid, A. M.: Report on a Botanical Excursion to the Sudd Region, Fouad I University Press, Cairo, Egypt, 1948.

Menenti, M.: Evaporation, in: Remote Sensing in Hydrology and Water Management, edited by: Schultz, G. A. and Engman, E. R., Springer Verlag, Heidelberg, Chapter 8, 157-188, 2000.

Mohamed, Y. A., Bastiaanssen, W. G. M., and Savenije, H. H. G.: Spatial variability of evaporation and moisture storage in the swamps of the upper Nile studied by remote sensing techniques, J. Hydrol., 289, 145-164, 2004.

Mohamed, Y. A., van den Hurk, B. J. J. M., Savenije, H. H. G., and Bastiaanssen, W. G. M.: Hydroclimatology of the Nile: Results from a regional climate model, Hydrol. Earth Syst. Sci., 9, 263278, 2005a.

Mohamed, Y. A., van den Hurk, B. J. J. M., Savenije, H. H. G., and Bastiaanssen, W. G. M.: The Impact of the Sudd wetland on the Nile Hydroclimatology, Water Resour. Res., 41, W08420, doi:10.1029/2004WR003792, 2005b.

Penman, H. L.: Vegetation and hydrology, Tech. Comm. No. 53, Commonwealth Bureau of Soils, Harpenden, England, pp. 125, 1963.

Rijks, D. A.: Evaporation from a papyrus swamp, Quart. J. Roy. Meteorol. Soc., 95, 643-649, 1969.

Savenije, H. H. G.: New definitions for moisture recycling and the relation with land-use changes in the Sahel, J. Hydrol., 167, 5778, 1995.

Schär, Ch., Lüthi, D., Beyerle, U., and Heise, E.: The SoilPrecipitation Feedback: A Process Study with a Regional Climate Model, J. Climate, 12(3), 722-741, 1999.

Stewart, J. B.: Modelling surface conductance of pine forest, Agriculture Forest Meteorology, 43, 19-35, 1988.

Sutcliffe, J. V. and Parks, Y. P.: The Hydrology of the Nile, IAHS Special Publication no. 5, IAHS Press, Institute of Hydrology, Wallingford, Oxfordshire OX10 8BB, UK, 1999.

Travaglia, C., Kapetsky, J., and Righini, G.: Monitoring wetlands for fisheries by NOAA AVHRR LAC thermal data. FAO/SDRN, Rome, Italy, 1995. 